\title{
Polymorphic outer-membrane proteins of Chlamydophila abortus are glycosylated
}

\author{
Evangelia Vretou, Panagiota Giannikopoulou and Evgenia Psarrou
}

Author for correspondence: Evangelia Vretou. Tel: +30 16478 873. Fax: +3016478 873. e-mail:vretou@mail.pasteur.gr

Department of

Microbiology, Hellenic Pasteur Institute, Vassilissis Sofias 127, Athens 11521 Greece

\begin{abstract}
Antigenic profiles of mono-, bi- and poly-specific monoclonal antibodies against 90 kDa polymorphic outer-membrane proteins (POMPs) and a 105 kDa POMP-related protein of Chlamydophila abortus ATCC VR 656', after one- and two-dimensional electrophoretic analysis, helped identify each one of the triplets POMP 90, 91A and 91B, and a POMP-related protein at $85 \mathrm{kDa}$. The lectin concanavalin A bound to the four POMPs and the POMP-related protein in a specific manner and the binding was sensitive to treatment with the amidase $\boldsymbol{N}$-endoglycosidase $\mathbf{F}$, suggesting the presence of small asparagine-linked oligosaccharide chains. The exposure of the five proteins on the chlamydial surface and the orientation of the attached oligosaccharide chains was examined by protease and endoglycosidase treatments of intact bacteria. The results were consistent with the concept that some of the oligosaccharides in the POMPs face outwards, possibly protecting the polypeptides from proteolytic enzymes, whereas the oligosaccharides in the 105 kDa POMPrelated protein are oriented inwards, thereby rendering the polypeptide chain accessible to proteases. A possible role for the $\boldsymbol{N}$-linked oligosaccharides in the POMPs might be the promotion of the proper folding and processing of these proteins.
\end{abstract}

Keywords: polymorphic outer-membrane protein family, bacterial glycoprotein, concanavalin A, two-dimensional electrophoresis

\section{INTRODUCTION}

Chlamydiae are obligate intracellular Gram-negative bacterial pathogens responsible for a wide variety of important human and animal infections (Stephens, 1999). The specific disease syndromes observed between and also within each species are highly diverse. Ovine abortion due to placental infection with Chlamydophila abortus (formerly immunotype 1 of Chlamydia psittaci; Everett et al., 1999) is one of the most common chlamydial diseases in animals, and has significant economic implications (Storz, 1971). Recently, interest in the biology of this micro-organism has been renewed with the ultimate goal of identifying vaccine candidates and improving disease diagnosis. In this context, our interest has been drawn to a particular Chlamydophila abortus protein that was originally identified as a major

Abbreviations: ConA, concanavalin A; EB, elementary body; MOMP, major outer-membrane protein; OG, n-octyl $\beta$-D-glucopyranoside; OMC, outer-membrane complex; PMP, polymorphic membrane protein; PNGase $\mathrm{F}, \mathrm{N}$-endoglycosidase $\mathrm{F}$ from Flavobacterium meningosepticum; POMP, polymorphic outer-membrane protein. immunogen and was used as part of a successful experimental vaccine (Cevenini et al., 1989; Tan et al., 1990). Further immunoblotting analysis with a panel of specific monoclonal antibodies (mAbs) revealed the presence of a triplet at $90 \mathrm{kDa}$ and a doublet at $85 \mathrm{kDa}$, instead of a single protein (Souriau et al., 1994; Vretou et al., 1996). Consequently, the term 'antigen family at $90 \mathrm{kDa}$ ' was introduced; it was suggested that the observed pleiomorphy might represent the differential trimming of a single protein or correspond to discrete products from different genes (Vretou et al., 1996). Screening of a $\lambda$ gt11gDNA expression library with affinity-purified antibodies against the $90 \mathrm{kDa}$ proteins identified two gene fragments (Longbottom et al., 1996). These were used to probe Southern blots of gDNA restriction enzyme digests and a family of related genes was identified. DNA sequence analysis showed the existence of four genes that encode three proteins, which, since they bore signal-peptide leaders, were named putative outer-membrane proteins (Longbottom et al., 1998a). With the completion of the sequencing of the genomes of Chlamydia trachomatis and Chlamydophila pneumoniae, it became apparent that the identified 
genes were the first members of a larger protein superfamily, referred to as the polymorphic membrane protein (PMP) family. The family's common features are the conserved motifs GGAI and FXXN, which are repeated in the N-terminal half of the proteins (Stephens et al., 1998; Kalman et al., 1999). In contrast to the PMPs, which are very heterogeneous, the polymorphic $90 \mathrm{kDa}$ POMPs of Chlamydophila abortus have a high degree of homology, as noted by Longbottom et al. (1998a), and might correspond to an expanded subclass. Analysis of the $90 \mathrm{kDa}$ protein family of Chlamydophila abortus by two-dimensional electrophoresis demonstrated the presence of four major protein species. The measured molecular masses and isoelectric points (pI) of three of the four proteins matched the predicted expression products of genes POMP $90 \mathrm{~A} / \mathrm{B}, 91 \mathrm{~A}$ and 91B. The fourth species, a protein cluster at $105 \mathrm{kDa}$, was characterized by antigenic cross-reactivity as being POMP-related. Furthermore, the two-dimensional map revealed an unusual and extensive degree of posttranslational modifications in each of the POMP-family members (Giannikopoulou et al., 1997). The presence of potential glycosylation and phosphorylation sites suggested by sequence analysis could account for the heterogeneity observed. In this paper we provide evidence that the POMPs, in particular POMP 91B and the POMP-related protein at $105 \mathrm{kDa}$, are glycosylated.

\section{METHODS}

Bacterial strains, growth conditions and purification. Chlamydophila abortus ATCC VR $656^{\mathrm{T}}$ was obtained from the American Type Culture Collection (Manassas, VA, USA). Chlamydiae were grown in McCoy cells (ATCC, Manassas, VA, USA) and were monitored regularly for mycoplasma contamination with 4',6-diamidine-2'-phenylindole dihydrochloride (DAPI, Boehringer Mannheim). Elementary bodies (EBs) were purified by centrifugation through a discontinuous gradient of gastrografin, as described previously (Vretou et al., 1996).

Metabolic labelling of chlamydiae. Labelling with $\operatorname{Tran}^{35} \mathrm{~S}$ Label was based on the procedure described for Chlamydia trachomatis by Goswami et al. (1990). Briefly, confluent McCoy cell cultures were infected with strain ATCC VR $656^{\mathrm{T}}$ in the presence of cycloheximide $\left(1 \mu \mathrm{g} \mathrm{ml}^{-1}\right)$. At $8-18 \mathrm{~h}$ postinfection, the medium was replaced with labelling medium (MEM with Earle's salts; ICN) supplemented with $5 \%(\mathrm{v} / \mathrm{v})$ of the normal amount of unlabelled methionine and cysteine, and $1 \mu \mathrm{g}$ emetine $\mathrm{ml}^{-1}$. Tran ${ }^{35} \mathrm{~S}$-Label ${ }^{35} \mathrm{~S}$ Escherichia coli hydrolysate labelling reagent, containing $70 \%$ L-methionine, $1175 \mathrm{Ci} \mathrm{mmol}{ }^{-1}, 43.5 \mathrm{TBq} \mathrm{mmol}^{-1}$; ICN) was added at a concentration of $500 \mu \mathrm{Ci}(18 \cdot 5 \mathrm{MBq})$ per $175 \mathrm{~cm}^{2}$ culture flask, and the $\mathrm{pH}$ was adjusted with $1 \mathrm{M}$ HEPES. Labelled EBs were isolated $72 \mathrm{~h}$ post-infection as usual. Sham-infected McCoy cells were labelled in parallel and used as a control.

Solubilization of outer-membrane complexes (OMCs). Purified EBs $\left(1.5 \mathrm{mg} \mathrm{ml}^{-1}\right)$ were incubated for $1 \mathrm{~h}$ at $4{ }^{\circ} \mathrm{C}$ in PBS $\left(0 \cdot 140 \mathrm{M} \mathrm{NaCl}, 0 \cdot 026 \mathrm{M} \mathrm{KCl}, 0.0014 \mathrm{M} \mathrm{KH_{2 }} \mathrm{PO}_{4}, 0 \cdot 008\right.$ $\mathrm{Na}_{2} \mathrm{HPO}_{4}$ ) containing $1 \%(\mathrm{v} / \mathrm{v}) \mathrm{N}$-lauroylsarcosine and then pelleted at $45000 \mathrm{~g}$ for $20 \mathrm{~min}$. The procedure was repeated once more and the combined EB pellets were extracted with $2 \%$ n-octyl $\beta$-D-glucopyranoside (OG; Sigma) containing $10 \mathrm{mM}$ DTT, for $1 \mathrm{~h}$ at $4{ }^{\circ} \mathrm{C}$. The solubilized material was probed on Western blots following gel electrophoresis.
Two-dimensional-PAGE and immunoblotting. Two-dimensional gel electrophoresis was performed essentially as described by Giannikopoulou et al. (1997) with a modification to the lysis buffer. EBs were lysed by heating $\left(5 \mathrm{~min}\right.$ at $\left.95^{\circ} \mathrm{C}\right)$ in a $4 \%$ CHAPS, $70 \mathrm{mM}$ DTT and $40 \mathrm{mM}$ Tris-base. Urea was added to a final concentration of $8 \mathrm{M}$ and the sample was left overnight before loading onto a non-linear immobilized $\mathrm{pH}$ gradient ( $\mathrm{pH} 3-10$; Pharmacia) and run at $110000 \mathrm{~V} \mathrm{~h}$, for $24 \mathrm{~h}$. The second-dimension run, silver staining, immunoblotting and detection with 3,3'-diaminobenzidine or chemiluminescence (Super Signal; Pierce) were performed according to published procedures (Giannikopoulou et al., 1997). Used nitrocellulose membranes were recycled by stripping off the bound ligands in $0.063 \mathrm{M}$ Tris $/ \mathrm{HCl}(\mathrm{pH} \mathrm{6.7)}, 100 \mathrm{mM} \beta$ mercaptoethanol and $2 \%$ SDS for $30 \mathrm{~min}$ at $70{ }^{\circ} \mathrm{C}$. Proteins captured on Western blots were visualized with Indian ink (black Pelican Fount Indian drawing ink) before or after immuno-enzyme detection.

mAbs. The anti-POMP mAbs 181 and 8976/073, and mAb 4H9 against the POMP-like protein at $105 \mathrm{kDa}$, have been described previously, as has mAb 188 against the major outer-membrane protein (MOMP) (Vretou et al., 1996; Giannikopoulou et al., 1997). mAb ABF8, an IgG3, which recognizes EF-Tu (heat-labile elongation factor) in Western blots after two-dimensional electrophoresis, was produced in this laboratory. mAbs EB3G2 and JA6C7, both reacting with the antigen family at $90 \mathrm{kDa}$, were kindly provided by $\mathrm{Dr} \mathrm{A}$. Rodolakis (INRA, Nouzilly, France), and have been described by Souriau et al. (1994). The anti-POMP mAbs were selected from a larger panel on the basis of their variant binding pattern to Western blots of whole EBs.

Lectin-binding assay. Concanavalin A (ConA)-binding assays were performed on nitrocellulose-immobilized proteins after separation by SDS-PAGE or by two-dimensional electrophoresis. The procedure was based on the lectin-binding assays of EBs immobilized on microtitre plates (Goswami et al., 1991). After blocking with $0 \cdot 2 \%$ Tween 20 in PBS for $1 \mathrm{~h}$ at $37^{\circ} \mathrm{C}$ and washing with PBS, biotinylated concanavalin A [Sigma; $1 \mu \mathrm{g}$ ConA per ml PBS containing 0.025\% Tween 20 (PBS-T), $1 \mathrm{mM} \mathrm{CaCl}$ and $1 \mathrm{mM} \mathrm{MgCl}_{2}$ ] was added. The haptenic sugar methyl $\alpha$-D-mannoside (FLUKA) was included as a control during the incubation with the lectin for $1 \mathrm{~h}$ at $37^{\circ} \mathrm{C}$. Membranes were washed three times with PBS-T and the bound lectin was detected with streptavidin-conjugated horseradish peroxidase and Super Signal (Pierce).

Treatment with $\boldsymbol{N}$-endoglycosidase F (PNGase F). Chlamydial proteins obtained by OG/DTT extraction were treated with the amidase PNGase F (from Flavobacterium meningosepticum; $500000 \mathrm{U} \mathrm{ml}^{-1}$; New England Biolabs), which cleaves between the innermost glucosamine and the asparagine residue on the peptide backbone. The chlamydial proteins were incubated for $1 \mathrm{~h}$ at $37^{\circ} \mathrm{C}$ either in solution (with $1500 \mathrm{U}$ PNGase $\mathrm{F} \mathrm{ml}^{-1}$ ), or in an immobilized form after transfer onto nitrocellulose paper (with $500 \mathrm{U}$ PNGase $\mathrm{F} \mathrm{ml}^{-1}$ in $0.05 \mathrm{M}$ sodium phosphate, $\mathrm{pH} 7 \cdot 5)$. To examine the orientation of the oligosaccharides, intact bacteria $(1.5 \mathrm{mg}$ intact bacteria per $\mathrm{ml}$ PBS containing $200 \mathrm{mM}$ sucrose and $5 \mathrm{mM} \mathrm{MgCl}_{2}$ ) were incubated for $2 \mathrm{~h}$ at $37^{\circ} \mathrm{C}$ with 7500,15000 or $30000 \mathrm{U}$ PNGase F ml ${ }^{-1}$. The EBs were pelleted, washed twice with PBS and analysed by SDS-PAGE and Western blotting.

Treatment of EBs with proteases. To investigate the surface exposure of proteins, purified EBs were incubated for $30 \mathrm{~min}$ at $37^{\circ} \mathrm{C}$ with increasing amounts of trypsin or proteinase $\mathrm{K}$ (both from Sigma) in PBS supplemented with $200 \mathrm{mM}$ sucrose and $5 \mathrm{mM} \mathrm{MgCl} \mathrm{m}_{2}$. The enzyme digestion was stopped with trypsin-inhibitor in the case of trypsin, and with $5 \mathrm{mM}$ PMSF 
in the case of proteinase $\mathrm{K}$. The EBs were pelleted and analysed by SDS-PAGE and Western blotting. For the trypsin control, trypsin was incubated in the presence of trypsininhibitor.

\section{RESULTS}

\section{Characterization of the polymorphic POMPs by mAbs}

When purified EBs of Chlamydophila abortus ATCC VR $656^{\mathrm{T}}$ were analysed on $20 \times 20 \mathrm{~cm}$ gels and stained with specific mAbs, three closely migrating bands at $90 \mathrm{kDa}$ and two bands at approximately $85 \mathrm{kDa}$, one more prominent than the other, were observed (Fig. 1). The panel of mAbs included mAbs 181 and 8976/073, which bound to all three closely migrating $90 \mathrm{kDa}$ bands, mAb EB3G2, which reacted with two of the three closely migrating bands, and mAb JA6C7, which recognized only the smallest (in size) of the $90 \mathrm{kDa}$ bands. Binding to the lower bands at $85 \mathrm{kDa}$ was common to all four of the mAbs. The POMP-related polypeptide at $105 \mathrm{kDa}$ was bound by mAb $4 \mathrm{H} 9$, as shown

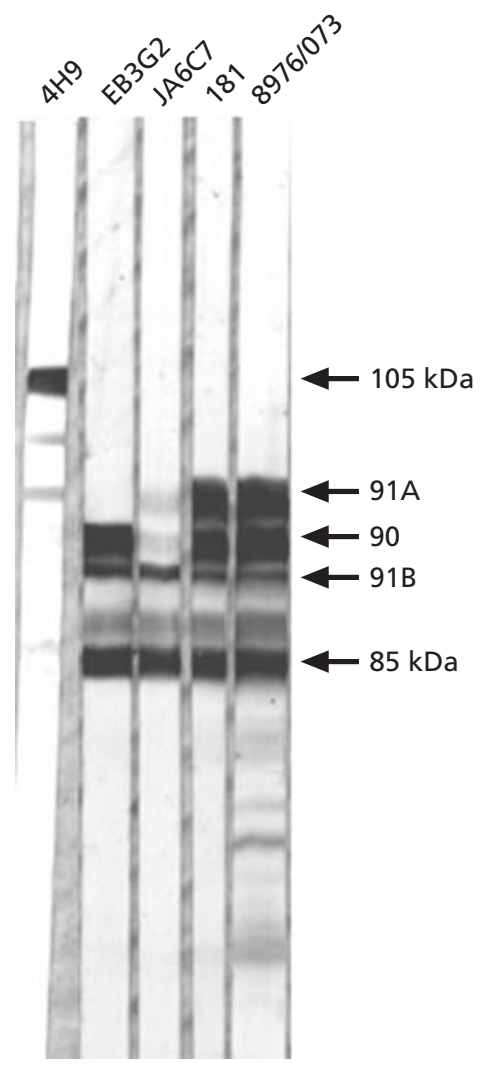

Fig. 1. Binding pattern of mAbs against the POMPs and the POMP-related polypeptides. Purified EBs were analysed on $20 \times 20 \mathrm{~cm} 10 \%$ SDS-polyacrylamide gels and immunoblotted with mAbs 4H9, EB3G2, JA6C7, 181 and 8976/073. Arrows on the right mark the position of the polypeptide at $105 \mathrm{kDa}$, the triplet at $90 \mathrm{kDa}$ and the doublet at $85 \mathrm{kDa}$. Order of migration and distinction between the three POMPs 91A, 90A/B and 91B was based on the fact that POMP 91A is larger than POMP 90 and the identification of POMPS $91 \mathrm{~B}$ and 90 as the antigens that reacted with $\mathrm{mAb}$ EB3G2.
(Giannikopoulou et al., 1997). Although each mAb displayed a characteristic antigen recognition pattern, a distinction between the three POMPs, 90A/B, 91A and $91 \mathrm{~B}$, on the basis of the specificity of the mAbs was not possible.

\section{Two-dimensional electrophoretic analysis}

Two-dimensional electrophoresis can distinguish between the $90 \mathrm{kDa}$ triplet bands, clearly separating POMP 91B from POMPs 90 and 91A on the basis of their different $\mathrm{pI}$ values, as reported by Giannikopoulou et al. (1997). The predicted pI of the entire POMP 91B is $5 \cdot 81$, whereas the $\mathrm{pI}$ values of POMP 91A and POMP 90 are 5.25 and $5 \cdot 09$, respectively. Fig. 2(a) shows an autoradiograph of ${ }^{35} \mathrm{~S}$-labelled purified EBs after twodimensional analysis in the immobilized $\mathrm{pH}$ gradient/ Dalton system (Amersham Pharmacia) depicting the position of the $90 \mathrm{kDa}$ triplet POMP proteins, as determined by their respective $\mathrm{pI}$ and molecular mass values. Immunoblotting of a comparable twodimensional gel with $\mathrm{mAb} 8976 / 073$ highlighted the position of the three POMPs (Fig. 2b), whereas the same membrane, stripped and restained with mAb EB3G2, clearly showed the position of POMP 90 and 91B (Fig. 2c). The specificity of these $\mathrm{mAbs}$ for their respective antigens was further confirmed by epitope mapping using synthetic peptides (unpublished results). The identification of POMP 91B and POMP 90 as the antigens reacting with $\mathrm{mAb}$ EB3G2, as well as the fact that POMP 91A is larger than POMP 90, led to the determination of the order of migration rate of these proteins in SDS-PAGE, from top to bottom, as POMP 91A, 90 and 91B (Fig. 1).

To test whether the POMPs have the ability to bind lectins, we incubated the same membrane that was probed with the mAbs (Fig. 2b, c) with biotinylated ConA (Fig. 2d). Two protein clusters, the POMP-related protein at $105 \mathrm{kDa}$ and POMP 91B, produced a strong lectin-binding signal. Some diffuse reaction was observed for POMP 90 and 91A, but only at the basic sides, although both of the whole clusters were entirely marked by mAbs EB3G2 and 8976/073 on the same membrane. Besides the strong signal generated by the $105 \mathrm{kDa}$ protein and POMP 91B, strong lectin-binding activity was also observed (from top to bottom) by spots at 98,85 and $60 \mathrm{kDa}$, by the MOMP, and by two spots below $30 \mathrm{kDa}$ (Fig. 2d).

\section{Treatment with PNGase F}

To ascertain whether the results observed in the twodimensional analysis demonstrated that the POMPs actually did contain glycan moieties, we studied the specificity of the lectin binding as well as the response to endoglycosidase treatment of the various POMPs. To this end, OMCs were solubilized with OG/DTT, analysed by SDS-PAGE, transferred to nitrocellulose membranes and stained with Indian ink and mAbs. The MOMP and the $90 \mathrm{kDa}$ triplet were the most prominent bands in the OG extract, as judged by the molecular 


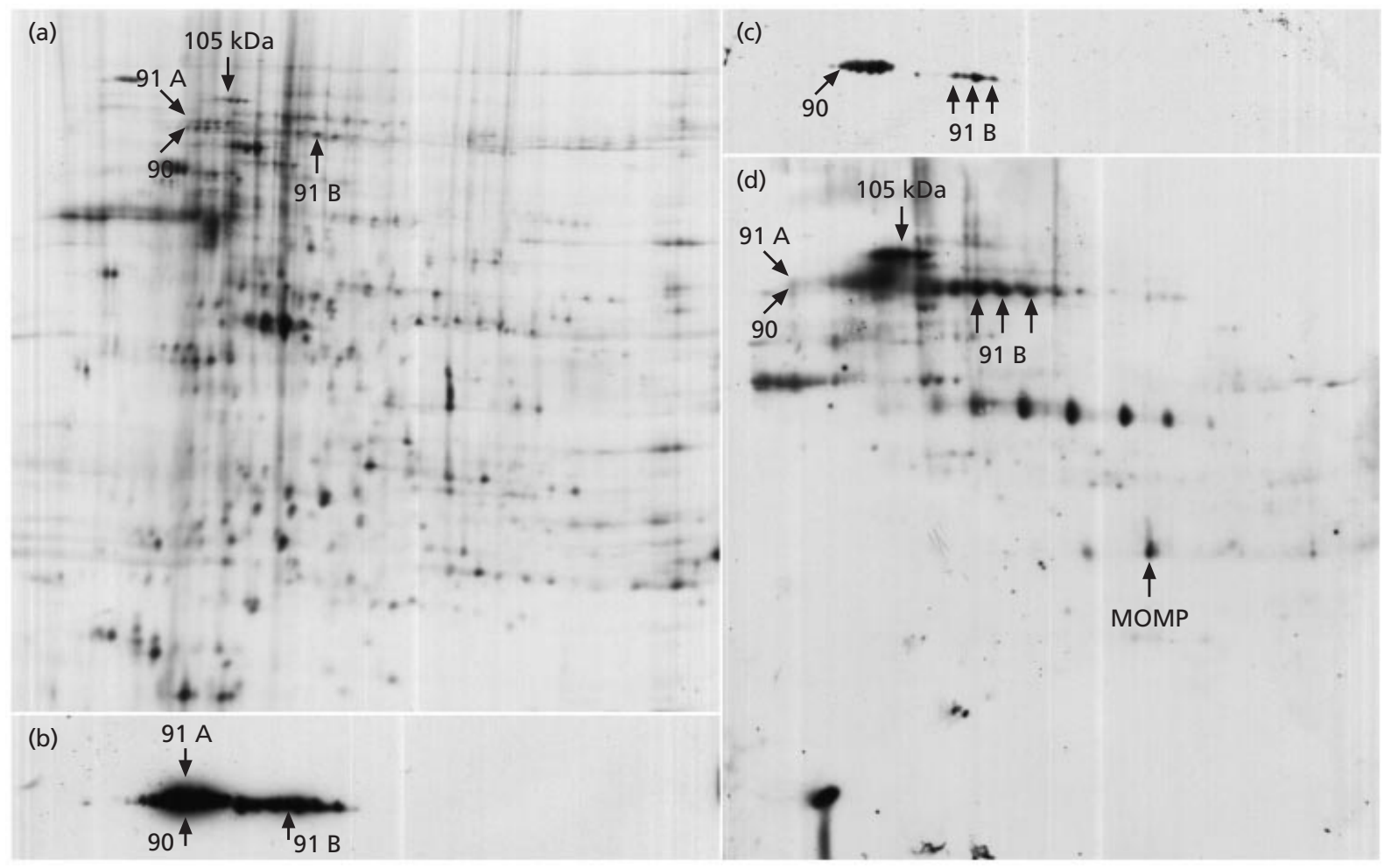

Fig. 2. Identification of ConA-binding POMPs by two-dimensional gel electrophoresis. (a) Autoradiograph of ${ }^{35} \mathrm{~S}$-labelled purified EBs separated on the immobilized $\mathrm{pH}$ gradient system $(\mathrm{pH}$ 3-10) from left to right in the first dimension, and by SDS-PAGE in the second dimension. (b-d) Corresponding Western blots. (b) Immunoblotting with mAb 8976/073, showing the whole region at $90 \mathrm{kDa}$. (c) Immunoblotting with $\mathrm{mAb} E B 3 G 2$, showing only POMPs 90 and 91B. (d) Binding of the lectin ConA by the POMPS and the MOMP. The position of POMPs at $105 \mathrm{kDa}, 91 \mathrm{~A}, 90$ and $91 \mathrm{~B}$, and of the MOMP are indicated by arrows.

masses in the blot stained with Indian ink (Fig. 3, lane 1) and the reactivity of specific mAbs 188 (anti-MOMP) and JA6C7 (anti-POMP 91B; Fig. 3, lane 2) against the OG extracts. Incubation with biotinylated ConA was performed in the absence (lane 3 ) and in the presence of the haptenic sugar methyl $\alpha$-D-mannoside (lane 5). The MOMP, and the POMPs at 85, 90 and $105 \mathrm{kDa}$ (lane 3) bound the lectin in a specific manner, since binding was inhibited by the presence of methyl $\alpha$-D-mannoside (lane 5). ConA reacts widely with mannose and specifically with biantennary high-mannose, hybrid and complex oligosaccharides from $\mathrm{N}$-linked oligosaccharides. Treatment of the proteins in the nitrocellulose membrane with the peptide-glycanase PNGase F, an enzyme that cleaves only $\mathrm{N}$-linked oligosaccharides, abolished binding of the lectin to the POMPs and decreased its reactivity with the MOMP (lane 4). Similar results were obtained when endoglycosidase treatment of the solubilized OMCs was performed in solution, before running the gel (lane 6). The membranes treated with ConA (lanes 3, 4 and 6) were probed with mAb JA6C7 immediately after the lectin-binding assay without the removal of the bound ConA (lanes 7-9). After stripping off $\mathrm{mAb} \mathrm{JA6C7}$, the membranes were subsequently reincubated with mAb 8976/073 (lanes 10 and 11, corresponding to membranes 3 and 6 ). The binding of both mAbs was unaffected by the treatment with the endoglycosidase whether it was in solution or on the membrane (compare lanes 7, 8 and 9, and lane 10 with 11), suggesting that their respective epitopes lie outside the oligosaccharide chains. Removal of the lectin ligand by the endoglycosidase treatment did not alter the migration of the $90 \mathrm{kDa}$ peptide (lanes 7 and 9, and 10 and 11), suggesting that the carbohydrate chains might be small. In summary, these data indicated that the POMPs at 85, 90 and $105 \mathrm{kDa}$ bear an asparagine-linked oligosaccharide.

Comparison of the two-dimensional electrophoretic maps of ${ }^{35}$ S-labelled EBs before and after treatment with the endoglycosidase PNGase F did not result in any substantial change of the relative positions of the multiple spots representing each one of the POMPs (data not shown). We therefore conclude that the multiplicity of the spots is not due to the glycan moiety, but must result from other post-translational modifications.

\section{Treatment with proteolytic enzymes}

The strong lectin-binding ability of POMP $91 \mathrm{~B}$ and the POMP-related protein at $105 \mathrm{kDa}$ prompted us to examine the surface exposure of the polypeptides and 


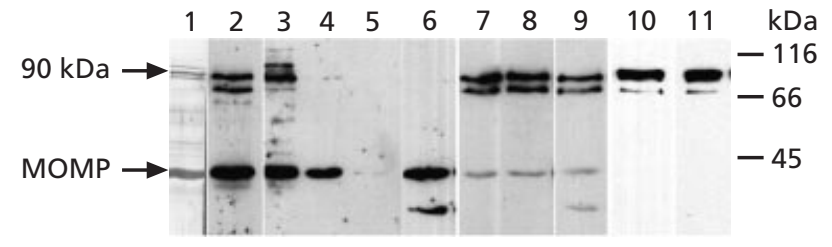

Fig. 3. ConA-binding proteins in OG/DTT-extracted OMC of Chlamydophila abortus ATCC VR $656^{\top}$ analysed on $12 \%$ SDSpolyacrylamide mini gels. Lanes: 1 , nitrocellulose membrane stained with Indian ink after transfer; 2, immunoblot with mAbs JA6C7 and 188 (anti-MOMP); 3-6, ConA-binding in the absence (lane 3 ) and in the presence of methyl $\alpha$-D-mannoside (lane 5), after treatment of the proteins on the membrane with PNGase $F$ (lane 4) and after treatment with PNGase $F$ in solution (lane 6, the lower band corresponds to the molecular mass of PNGase F); 7-9, correspond to lanes 3, 4 and 6 when reacted with mAb JA6C before PNGase $F$ treatment (lane 7), after PNGase $F$ treatment on the membrane (lane 8) or in solution (lane 9); 10 and 11, immunoblot with mAb 8976/073 before (lane 10) and after treatment with PNGase F (lane 11). Molecular masses are on the right side of the gel images. The positions of the triplet at $90 \mathrm{kDa}$ and of the MOMP are indicated on the left.

the attached glycan moieties. To this end, whole purified EBs suspended in PBS containing sucrose and $\mathrm{Mg}^{2+}$ were incubated at $37^{\circ} \mathrm{C}$ with trypsin, pelleted, analysed by SDS-PAGE, transferred to a nitrocellulose membrane and probed with $\mathrm{mAb} 4 \mathrm{H} 9$, which was specific for the $105 \mathrm{kDa}$ protein, and the panel of anti-POMP mAbs shown in Fig. 1. Exposure of purified EBs to trypsin at 10:1 (w/w, i.e. $100 \mu \mathrm{g}$ intact $\mathrm{EBs} \mathrm{ml}^{-1}$ to $10 \mu \mathrm{g}$ trypsin $\mathrm{ml}^{-1}$ ) for $30 \mathrm{~min}$ resulted in the cleavage of the $105 \mathrm{kDa}$ protein and the generation of an intermediate fragment at $66 \mathrm{kDa}$ and a stable fragment at $32 \mathrm{kDa}$ (both marked by asterisks in Fig. 4a). To check that trypsin did not

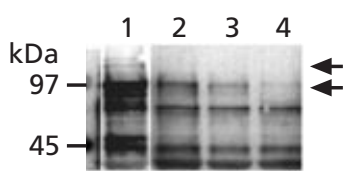

(a)

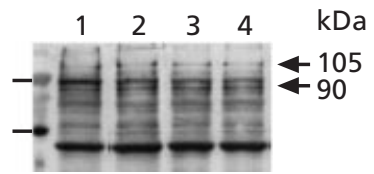

(b)
Fig. 5. Sensitivity of the ConA ligands to proteinase $K$ and PNGase $\mathrm{F}$ treatment. Intact EBs $\left(1.5 \mathrm{mg} \mathrm{ml}^{-1}\right)$ were incubated with increasing concentrations of proteinase $\mathrm{K}$ and PNGase $\mathrm{F}$. After transfer onto nitrocellulose the membranes were incubated with biotinylated ConA and peroxidase-conjugated streptavidin. (a) Lanes: 1 , untreated control; $2,10 \mu \mathrm{g}$ proteinase $\mathrm{K} \mathrm{ml}^{-1} ; 3,50 \mu \mathrm{g}$ proteinase $\mathrm{K} \mathrm{ml}^{-1}$; and $4,100 \mu \mathrm{g}$ proteinase $\mathrm{K} \mathrm{ml}^{-1}$. (b) Lanes: 1, untreated control; 2, $7500 \mathrm{U}$ PNGase $\mathrm{F} \mathrm{ml}^{-1}$; 3, $15000 \mathrm{U}$ PNGase $\mathrm{F} \mathrm{ml}^{-1}$; and 4, $30000 \mathrm{U}$ PNGase $\mathrm{F} \mathrm{ml}^{-1}$. Molecular mass standards $(\mathrm{kDa})$ are on the left. The arrows on the right side indicate the positions of the POMP-like protein at $105 \mathrm{kDa}$ and the POMPs at $90 \mathrm{kDa}$.

penetrate the chlamydial cell envelope, even in the presence of excess $\mathrm{Mg}^{2+}$ ions, which are required for maximal lipopolysaccharide cross-linking (Vretou et al., 1992), we probed the electro-transferred digest with $\mathrm{mAb}$ ABF8, which reacts with EF-Tu. As shown in Fig. 4(b), treatment of EBs with increasing concentrations of trypsin (EB:trypsin ratio 20:1 and 10:1, w/w, respectively) resulted in no decrease in the binding pattern displayed by anti-EF-Tu, suggesting that this cytoplasmic protein remained intact after tryptic digestion. Similar results were obtained when the digests were probed with an anti-DnaK mAb (data not shown).

None of the three POMPs at $90 \mathrm{kDa}(90,91 \mathrm{~A}$ and 91B) was cleaved under the conditions needed to digest the POMP-like $105 \mathrm{kDa}$ protein, although there was a decrease in the intensity of the original signal. When a
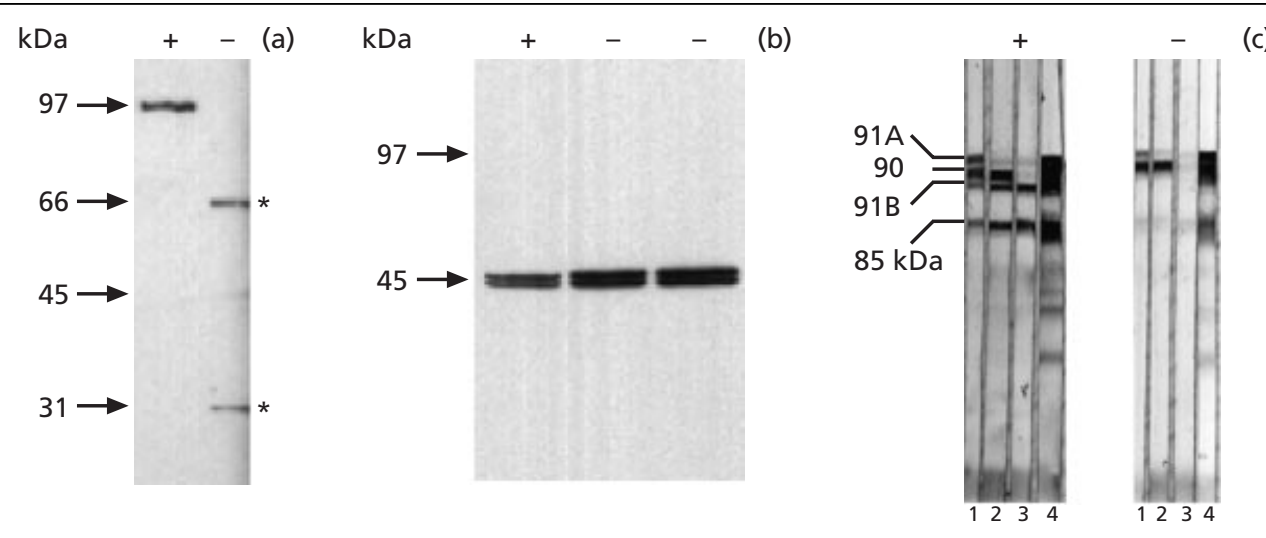

(c)

Fig. 4. Sensitivity of the POMPs to trypsin. (a) Purified EBs in PBS containing sucrose and $\mathrm{Mg}^{2+}$ were treated with trypsin $(10: 1, \mathrm{w} / \mathrm{w})$ for $30 \mathrm{~min}$ at $37^{\circ} \mathrm{C}$, in the presence $(+)$ and absence $(-)$ of trypsin inhibitor, analysed on $10 \%$ SDS-PAGE mini gels, transferred to nitrocellulose membranes and reacted with mAb 4H9 against the POMP-like protein at $105 \mathrm{kDa}$. Asterisks on the right indicate the position of the tryptic fragments at 66 and at $32 \mathrm{kDa}$ resulting from the digestion of $105 \mathrm{kDa}$ POMP-like protein. Molecular masses are on the left. (b) EBs were treated with trypsin (20:1 and 10:1, w/w, respectively, as above) resolved on $12 \%$ SDS-PAGE gels, transferred to nitrocellulose and reacted with mAb ABF8 against EF-Tu. Molecular mass standards are on the left. (c) EBs were incubated for 30 min with trypsin $(10: 100$, w/w), in the presence $(+$, control) and in the absence of trypsin-inhibitor $(-)$, pelleted, and analysed on $20 \times 20 \mathrm{~cm} 10 \%$ SDSpolyacrylamide gels. Western blotting was done with mAbs 181 (lane 1), EB3G2 (lane 2), JA6C7 (lane 3) and 8976/073 (lane 4). The positions of POMP 91A, 90, 91B and at the POMP at $85 \mathrm{kDa}$ are marked on the left. 
Table 1. Characteristics of the POMPs and POMP-related proteins studied

\begin{tabular}{|llcc|}
\hline Protein & \multicolumn{1}{c|}{ Reacting mAbs } & $\begin{array}{c}\text { ConA } \\
\text { binding }\end{array}$ & $\begin{array}{c}\text { Trypsin } \\
\text { sensitivity }\end{array}$ \\
\hline POMP at 105 kDa & $4 \mathrm{H} 9$ & + & + \\
POMP 91A & $181,8976 / 073$ & $\pm^{*}$ & - \\
POMP 90 & EB3G2, 181, 8976/073 & $\pm^{*}$ & - \\
POMP 91B & JA6C7, EB3G2, 181, 8976/073 & + & + \\
POMP at $85 \mathrm{kDa}$ & EB3G2, JA6C7, 181,8976/073 & + & + \\
\hline
\end{tabular}

* Restricted reactivity as shown in Fig. 2(d).

larger excess of trypsin was applied (EB:trypsin 1:10, $\mathrm{w} / \mathrm{w}$ ) the lowest band in the triplet, the one stained by $\mathrm{mAb}$ JA6C7, disappeared, suggesting that POMP 91B was cleaved (Fig. 4c, lane 3). The band at $85 \mathrm{kDa}$ was also affected; however, POMP 91A and POMP 90 were not and remained visible even at this large excess of trypsin (Fig. 4c, lanes 1-3). Since trypsin-sensitive sites did not seem to be particularly surface-accessible in the POMPs at $90 \mathrm{kDa}$, we examined the surface exposure of the proteins and their oligosaccharide chains with proteinase $\mathrm{K}$ and PNGase $\mathrm{F}$ under non-denaturing conditions. Whole, purified EBs were incubated with increasing concentrations of proteinase $\mathrm{K}$ and the endoglycosidase, lysed, analysed by SDS-PAGE, electrotransferred onto membranes and probed with ConA. As shown in Fig. 5(a) as little as $10 \mu \mathrm{g}$ proteinase $\mathrm{K} \mathrm{ml}^{-1}$ completely digested the POMP at $105 \mathrm{kDa}$. In the region of $90 \mathrm{kDa}$ the ConA signal decreased gradually and remained visible even when the enzyme concentration was raised to $100 \mu \mathrm{g}$ proteinase $\mathrm{K} \mathrm{ml}^{-1}$. Parallel treatment of intact EBs with PNGase F resulted in a dosedependent decrease of the ConA signal of the POMPs at $90 \mathrm{kDa}$, which was more pronounced at $15000 \mathrm{U}$ enzyme $\mathrm{ml}^{-1}$ (Fig. $5 \mathrm{~b}$ ). In contrast, the intensity of the ConA-binding POMP at $105 \mathrm{kDa}$, identified with $\mathrm{mAb}$ $4 \mathrm{H} 9$ on the same membrane, was not affected by the glycosidase at any concentration of the enzyme (Fig. $5 \mathrm{~b}$ ). These observations taken together suggested that the lectin ligand(s) in the POMPs at $90 \mathrm{kDa}$ are partially accessible at the surface of intact EBs, whereas glycosylation sites in the POMP at $105 \mathrm{kDa}$ are not surface exposed, although they are situated in a polypeptide chain that is easily accessible to proteases. The properties of the POMPs and POMP-related proteins which were studied are summarized in Table 1.

\section{DISCUSSION}

The three proteins of Chlamydophila abortus ATCC VR $656^{\mathrm{T}}$, POMP 90, 91A and 91B share over $80 \%$ homology, and migrate very closely in conventional SDS-polyacrylamide mini gels. They can be separated on $20 \times 20 \mathrm{~cm}$ gels, as shown previously (Vretou et al., 1996), and can be identified by two-dimensional electrophoresis (Giannikopoulou et al., 1997). In the present study we have established mAbs JA6C7 and EB3G2 as markers for two proteins, POMPs 90 and 91B, on the basis of antigenic profiles in one- and two-dimensional gels. POMP 91B was identified as the antigen of the mono-specific antibody JA6C7, whereas mAb EB3G2 marked both POMPs 90 and 91B. The POMP-related protein at $85 \mathrm{kDa}$ also bears the epitope of mAb JA6C7 (Fig. 1) and could represent a processed or differently folded protein related to POMP 91B. mAb $4 \mathrm{H} 9$ marked the POMP-related protein at $105 \mathrm{kDa}$; however, the gene encoding this protein is still to be identified. The three mAbs, JA6C7, EB3G2 and 4H9, should prove to be useful markers for future studies.

We have shown in this study that the $85 \mathrm{kDa}$ and $105 \mathrm{kDa}$ POMP-like proteins and the POMP triplet at $90 \mathrm{kDa}$ have short asparagine-linked mannose-containing carbohydrate chains, and have further addressed the issue of the exposure of their polypeptide chains and the orientation of the attached oligosaccharides. All five proteins were released from the OMC by $O G$ and reducing agents (Fig. 3). The results from the protease digestion experiments suggested that the exposure of the POMP at $105 \mathrm{kDa}$ and at $90 \mathrm{kDa}$ was very different (Fig. $4 a, c)$. The former is particularly sensitive to trypsin, which cleaves the molecule down to a $32 \mathrm{kDa}$ fragment possibly anchored in the outer membrane (Fig. 4a). The POMPs at $90 \mathrm{kDa}$ were resistant to trypsin with the exception of POMP 91B and the POMP-like protein at $85 \mathrm{kDa}$, which were cleaved with a large excess of trypsin (Fig. 4c). Tanzer et al. (2001) reported recently that two of the six identified POMPs in Chlamydia psittaci strain $6 \mathrm{BC}$ were sensitive to trypsin; however, no relative differences between the POMPs regarding their sensitivity to the protease were noted. Previous experiments using electron microscopy have shown that the epitope of mAb 181 is accessible to the antibody on the surface of EBs. These data have led to the suggestion that at least one of the three POMPs at $90 \mathrm{kDa}$ reacting with this $\mathrm{mAb}$ is surface exposed (Longbottom et al., 1998b). We examined the orientation of the oligosaccharides attached to the POMPs by treating EBs with glycosidase under non-denaturing conditions. The data showed that the ConA ligand in the large POMP-related molecule was not accessible to the enzyme, which was in contrast to the ConA ligands in the POMPs at $90 \mathrm{kDa}$, which were partially cleaved. These results are consistent with the concept that some of the oligosaccharides in the $90 \mathrm{kDa}$ proteins faced outwards, 
possibly protecting the polypeptides from proteolytic enzymes, whereas the oligosaccharides in the large POMP were oriented inwards, thus rendering the polypeptide chain accessible to proteases.

The addition of carbohydrates to proteins is the most common post-translational modification in the eukaryotic cell. Oligosaccharide linkage occurs either at the asparagine residue of the consensus tripeptides N-X$\mathrm{S} / \mathrm{T}$, or at a serine or threonine residue. In prokaryotes, glycosylation has been considered uncommon for a long time, being restricted to proteins in archaeal and eubacterial S-layers (Lechner \& Wieland, 1989; Messner \& Sleytr, 1991). The best-studied prokaryotic glycoproteins remain the glycoproteins of the S-layer. However, an increasing series of surface- or membraneassociated bacterial proteins, bearing unambiguously demonstrated glycosidic linkages, have been reported recently (Schäffer et al., 2001). Besides the oligosaccharide linkages at asparagine and serine or threonine residues, similar to those encountered in the eukaryotic cell, protein glycosylation in prokaryotes may also occur at tyrosine residues and shows in general greater diversity in glycan composition (Schäffer et al., 2001). $\mathrm{N}$-Glycosidic linkages are rare in prokaryotes; when we scanned the sequences of POMPs 90, 91A and 91B for potential glycosylation sites (program Scanprosite) 17, 16 and 19 putative $N$-linked glycosylation sites were detected, respectively. This is a relatively high number compared to the MOMP, where only three potential $\mathrm{N}$ glycosylation sites were found. Nine of these consensus tripeptides (ten for POMP 91B) were located in the Nterminus of the amino acid sequences within a 200 amino acid domain (amino acids 27-223 in POMP 91B). It is worth noting that immunoelectronic microscopy has demonstrated that this domain is accessible to antibodies utilized in this study on the chlamydial outermembrane surface (Longbottom et al., 1998b). The majority of the remaining sites reside in the second half of the C-terminal part of the molecules. It is interesting that many of the potentially glycosylated asparagine residues coincide with the asparagine in the signature motif FXXN, which is common to the POMPs and the extended PMP family in Chlamydia trachomatis and Chlamydophila pneumoniae. Six out of nine FXXN motifs in POMP90, four out of eight motifs in 91A, and five out of seven in POMP91B are theoretically potential glycosylation sites. Three of these potentially glycosylated FXXN motifs precede the three GGAI signatures in the POMPs. FXXN motifs which are also consensus sites for glycosylation are found in $C$. pneumoniae orthologues, i.e. two sites in PMP 9. However, the strong ConA binding of POMP 91B compared to POMP 90 and $91 \mathrm{~A}$ as shown in Fig. 2(d), suggests that only a few of the consensus glycosylation sites may bear an asparagine-linked carbohydrate chain. The sensitivity of the lectin binding to treatment with the asparaginyl- $\mathrm{N}$-acetylglucosamine amidase, as shown in Fig. 3, provides additional support for the existence of covalently $\mathrm{N}$-linked glycosylation sites in the POMPs, since lectin binding alone might be caused by firmly associated non-covalently linked saccharides. Further chemical characterization, such as protease digestion and peptide analysis by mass-spectrometry, is needed to allow the exact identification of the glycosylation sites and the carbohydrate constituents in the POMPs.

Oligosaccharide chains are often involved in cell recognition and regulatory processes because of their diversity and specificity. In Chlamydia spp. carbohydrates have been implicated early on in the interaction of the bacterium with the host cell. Stimulation by the lectin wheatgerm agglutinin (WGA) on the attachment of HeLa, but not McCoy, cell-grown C. trachomatis has been reported, suggesting that enzymes from the host cell may contribute to the glycosylation of chlamydial proteins (Bose et al., 1983). WGA-binding proteins were demonstrated in unheated, OG-extracted preparations of the same species (Goswami et al., 1991). The lectinbinding ligand was isolated as the glycan moiety of the MOMP that interfered with the attachment process (Swanson \& Kuo, 1994). It is conceivable that the surface-exposed glycan moieties in the POMPs at $90 \mathrm{kDa}$ (Fig. 5b) play a role in the attachment and entry process of Chlamydophila abortus to the host cell. However, the short carbohydrate chains suggested from this study do not support a role in the host-attachment process through the oligosaccharide chains.

The genomic organization of the POMPs in the N-and C-terminal domains (Longbottom et al., 1998a), the different surface exposure of these domains on the EB surface (Longbottom et al., 1998b), as well as the sequence similarity of the PMPs with the RompA protein of Rickettsia spp. and the filamentous haemagglutinin of Bordetella pertussis (Grimwood \& Stephens, 1999), have brought the POMPs into association with the class IV secretion molecules, the autotransporters. Christiansen et al. (2000) recently reported the structural similarity between the C-terminal part of the PMPs and the transmembrane $\beta$-barrel in autotransporters. Moreover, they showed that antibodies against nondenatured OMCs of C. pneumoniae recognized on the surface of $E$. coli a stably expressed construct which consisted of the N-terminal part of Omp 4 and the $\beta$ barrel of the E. coli autotransporter AIDA. Such transport mechanisms require extensive folding and processing, particularly when the molecules are rich in cysteine as is the case with the POMPs. In the eukaryotic cell, $\mathrm{N}$-linked oligosaccharides affect the folding process of polypeptide chains. A great majority of $N$-linked glycans occur in locations of compact $\beta$-turns, and oligosaccharides may orient peptide segments toward the surface of protein domains, mimicking chaperones (Helenius \& Aebi, 2001). On this basis, we speculate that a possible role for the $\mathrm{N}$-linked oligosaccharides in the POMPs might be the promotion of the proper folding and processing of these proteins as parts of a sophisticated transport system. Alternatively, short oligosaccharide chains on membrane-anchored proteins, when cross-linked, could provide the EB with additional stability and act as analogues of peptidoglycan. 


\section{ACKNOWLEDGEMENTS}

We thank Dr A. Rodolakis (INRA, Nouzilly, France) for the gift of antibodies. We are indebted to Dr S. K. Bose (Athens, Greece) and to Dr D. Longbottom (The Moredun Research Institute, Edinburgh, UK) for editing the manuscript.

\section{REFERENCES}

Bose, S. K., Smith, G. B. \& Paul, R. G. (1983). Influence of lectins, hexoses, and neuraminidase on the association of purified elementary bodies of Chlamydia trachomatis UW-31 with HeLa cells. Infect Immun 40, 1060-1067.

Cevenini, R., Moroni, A., Sambri, V., Perini, S. \& La Placa, M. (1989). Serological response to chlamydial infection in sheep, studied by enzyme-linked immunosorbent assay and immunoblotting. FEMS Microbiol Immunol 47, 459-464.

Christiansen, G., Pedersen, A. S., Hjerno, K., Vandahl, B. \& Birkelund, S. (2000). Potential relevance of Chlamydia pneumoniae surface proteins to an effective vaccine. J Infect Dis 181, S528-S537.

Everett, K. D. E., Bush, R. M. \& Andersen, A. A. (1999). Emended description of the order Chlamydiales, proposal of Parachlamydiaceae fam. nov. and Simkaniaceae fam. nov., each containing one monotypic genus, revised taxonomy of the family Chlamydiaceae, including a new genus and five new species, and standards for the identification of organisms. Int J Syst Bacteriol 49, 415-440.

Giannikopoulou, P., Bini, L., Simitsek, P. D., Pallini, V. \& Vretou, E. (1997). Two-dimensional electrophoretic analysis of the protein family at $90 \mathrm{kDa}$ of abortifacient Chlamydia psittaci. Electrophoresis 18, 2104-2108.

Goswami, P. C., Vretou, E. \& Bose, S. K. (1990). Extensive heterogeneity of the protein composition of Chlamydia trachomatis following serial passage in two different cell lines. J Gen Microbiol 136, 1623-1629.

Goswami, P. C., Vretou, E. \& Bose, S. K. (1991). Host passagedependent wheat germ agglutinin-binding proteins of Chlamydia trachomatis. FEMS Microbiol Lett 81, 53-56.

Grimwood, J. \& Stephens, R. S. (1999). Computational analysis of the polymorphic membrane protein superfamily of Chlamydia trachomatis and Chlamydia pneumoniae. Microb Comp Genomics 4, 187-201.

Helenius, A. \& Aebi, M. (2001). Intracellular functions of $N$-linked glycans. Science 291, 2364-2369.

Kalman, S., Mitchell, W., Marathe, R. \& 7 other authors (1999). Comparative genomes of Chlamydia pneumoniae and C. trachomatis. Nat Genet 21, 385-389.

Lechner, J. \& Wieland, F. (1989). Structure and biosynthesis of prokaryotic glycoproteins. Annu Rev Biochem 58, 173-194.
Longbottom, D., Russell, M., Jones, G. E., Lainson, F. A. \& Herring, A. J. (1996). Identification of a multigene family encoding the $90 \mathrm{kDa}$ proteins of the ovine abortion subtype of Chlamydia psittaci. FEMS Microbiol Lett 142, 277-281.

Longbottom, D., Russell, M., Dunbar, S. M., Jones, G. E. \& Herring, A. J. (1998a). Molecular cloning and characterization of the genes encoding the highly immunogenic cluster at 90-kilodalton envelope proteins from the Chlamydia psittaci subtype that causes abortion in sheep. Infect Immun 66, 1317-1324.

Longbottom, D., Findlay, J., Vretou, E. \& Dunbar, S. M. (1998b). Immunoelectron microscopic localisation of the OMP90 family on the outer membrane surface of Chlamydia psittaci. FEMS Microbiol Lett 164, 111-117.

Messner, P. \& Sleytr, U. B. (1991). Bacterial surface layer glycoproteins. Glycobiology 1, 545-551.

Schäffer, C., Graninger, M. \& Messner, P. (2001). Prokaryotic glycosylation. Proteomics 1, 248-251.

Souriau, A., Salinas, J., De Sa, C., Layashi, K. \& Rodolakis, A. (1994). Identification of subspecies- and serotype 1-specific epitopes on the 80- to 90-kilodalton protein region of Chlamydia psittaci that may be useful for diagnosis of chlamydial induced abortion. Am J Vet Res 55, 510-514.

Stephens, R. S. (editor) (1999). Chlamydia: Intracellular Biology, Pathogenesis, and Immunity. Washington, DC: American Society for Microbiology.

Stephens, R. S., Kalman, S., Lammel, C. \& 9 other authors (1998). Genome sequence of an obligate intracellular pathogen of humans: Chlamydia trachomatis. Science 282, 754-759.

Storz, J. (1971). Chlamydia and Chlamydia-induced Diseases. Springfield, IL: Charles C. Thomas.

Swanson, A. F. \& Kuo, C.-C. (1994). Binding of the glycan moiety of the major outer-membrane protein of Chlamydia trachomatis to HeLa cells. Infect Immun 62, 24-28.

Tan, T. W., Herring, A. J., Anderson, I. E. \& Jones, G. E. (1990). Protection of sheep against Chlamydia psittaci infection with a subcellular vaccine containing the major outer membrane protein. Infect Immun 58, 3101-3108.

Tanzer, R. J., Longbottom, D. \& Hatch, T. P. (2001). Identification of polymorphic outer membrane proteins of Chlamydia psittaci 6BC. Infect Immun 69, 2428-2434.

Vretou, E., Psarrou, E. \& Spiliopoulou, D. (1992). The role of lipopolysaccharide in the exposure of protective antigenic sites on the major outer membrane protein of Chlamydia trachomatis. J Gen Microbiol 138, 1221-1227.

Vretou, E., Loutrari, H., Mariani, L. \& 7 other authors (1996). Diversity among abortion strains of Chlamydia psittaci demonstrated by inclusion morphology, polypeptide profiles and monoclonal antibodies. Vet Microbiol 51, 275-289.

Received 11 April 2001; revised 14 August 2001; accepted 20 August 2001. 